\title{
An erythematous plaque on the nose: What is your diagnosis?
}

\author{
Faten Rabhi', Refka Frioui', Nada Mansouri², Kahena Jabeur', Abderraouf Dhaoui' \\ ${ }^{1}$ Department of Dermatology, Military Hospital of Tunis, 1008, Monfleury, Tunis, Tunisia, ${ }^{2}$ Department of Pathology, Military \\ Hospital of Tunis, 1008, Monfleury, Tunis, Tunisia.
}

Corresponding author: Faten Rabhi, MD, E-mail: Rafkouna1993@gmail.com

\section{CASE REPORT}

A 55-year-old male presented to our dermatology department with 3 months history of an asymptomatic and red raised plaque on the nose. There was no history of discoloration of skin prior to the development of this lesion. His only medical history was type 2 diabetes and high blood pressure. He had never undergone radiation therapy. On clinical examination, a well-defined glistening bluish-erythematous plaque $3 * 3 \mathrm{~cm}$ was present on the nose which was soft and non-tender (Fig. 1). Nasal mucosa was completely spared. No cervical lymphadenopathy was found. Head and neck examination was unremarkable. A CT scan of head and neck founded a soft tissue mass without infiltration of underlying structures.

\section{DERMOSCOPY FINDINGS}

The dermoscopy revealed homogeneous pattern with combinations of colors (pinkish, bluish, and violaceous) and whitish veil areas without well-defined vessels or lacunae (Fig. 2).

\section{HISTOLPATHOLOGY}

The histological examination of the first biopsy revealed a benign fibtoblastic reaction around normal vessels with fibrin deposits and without nuclear atypia. The second skin biopsy showed anastomosing vascular structures of variable diameter in the dermis, lined by plump endothelial cells with marked cellular, nuclear polymorphism and occasional mitosis, dissecting the collagen bundles (Fig. 3a). On immunohistochemistry,

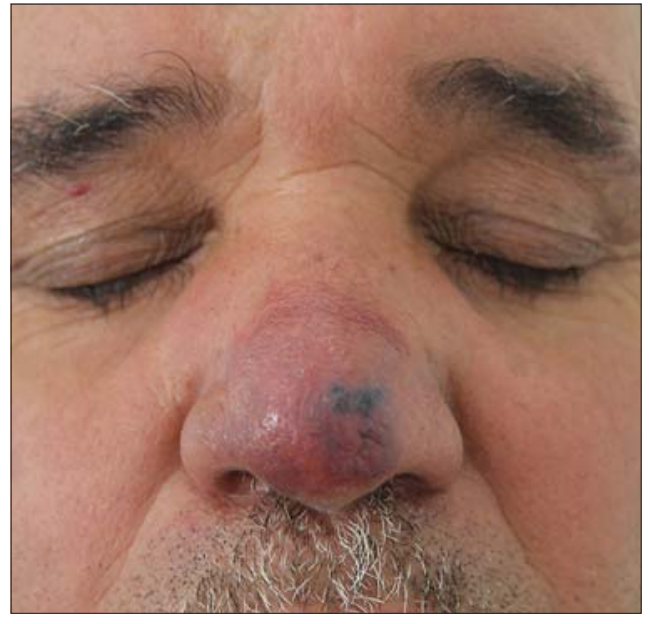

Figure 1: A well-defined glistening bluish-erythematous plaque $3 * 3$ $\mathrm{cm}$ on the nose.

tumor cells expressed CD31, ERG, CD34 and VIII Factor. Ki67 was high in tumor cells (60\%) (Fig. 3b).

\section{WHAT'S YOUR DIAGNOSIS?}

Answer: Cutaneous Angiosarcoma

\section{DISCUSSION}

Herein we report a case of CA in a particular site and at an early age. CA is an uncommon malignant neoplasm arising from endothelial cells that line the blood vessels. While sarcomas account for $<1 \%$ of all malignancies, CA constitutes only $1 \%-2 \%$ of all soft tissue sarcomas [1]. It has been categorized into three clinical variants [2-4]: sporadic CA of the head and neck, postradic CA and lymphedema-associated CA. Herein we present a case of CA of the head and neck

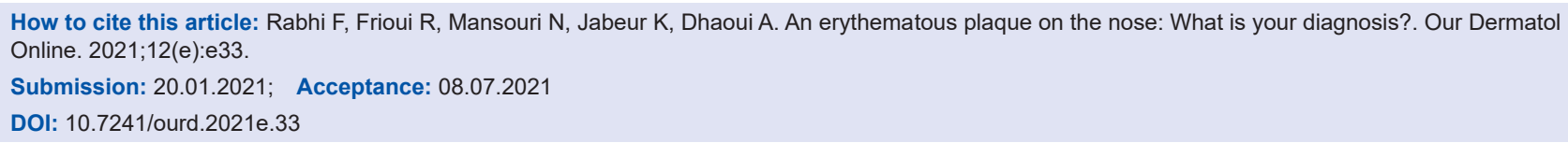




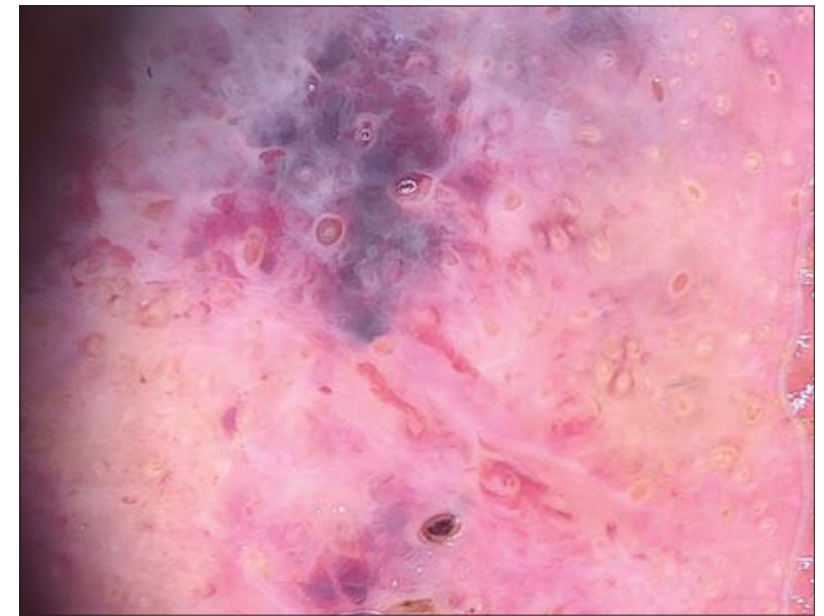

Figure 2: Homogeneous pattern with combinations of colors (pinkish, bluish, and violaceous) and whitish veil areas.

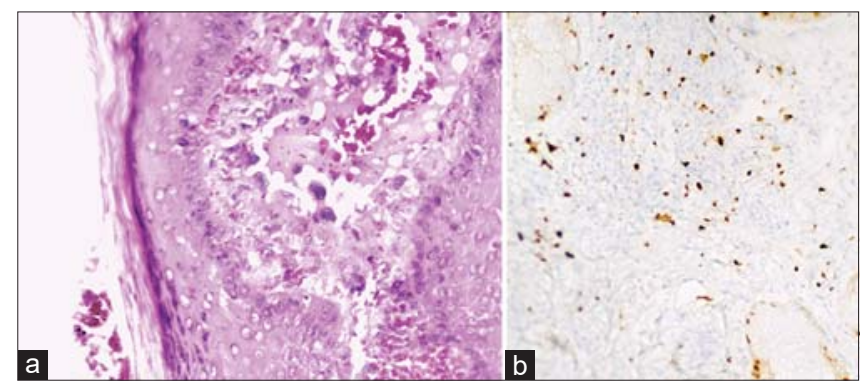

Figure 3: (a) HE x 400. Vascular proliferation with atypical endothelial cells (arrow). (b) IHC x 200, Elevated proliferation index Ki67.

which is the most common. This aggressive vascular neoplasm predominantly affects elderly patients in the seventh to eighth decade of life without pre-existing condition [5]. Our patient, however, was in the mid- fifties. The tumor is localized mostly to the upper half of the face and the scalp. However, ACs occurring in the nasal cavity or on the external nose, as in our case, have been rarely reported [6].

The diagnosis of CA is often delayed by the variable presentation and the benign appearance of the lesion. Ill-defined bruise like area, as we show in our patient, or facial edema with minimal erythema are the initial signs. Progressively more indurated plaques appear with nodular components. Ulcerated and bleeding lesions represent signs of advanced diseases [5]. These non-specific aspects could mimic different types of lesions: lupus pernio, benign inflammatory disease, hemangiomas, amelanotic melanoma and kaposy sarcoma [7].

An early dermatological evaluation and an appropriate dermoscopic examination may help avoid a delayed diagnosis. As seen in our case, dermoscopy revealed the classic colors of vascular lesions, a graduation of red, purple, and blue with whitish veil areas. Various color gradiation may be an important dermoscopic feature of CA, since it is not found in common purpura and ecchymosis [8]. This structureless pattern prompted us to redo the biopsy.

Only the anatomopathological examination can confirm the diagnosis. The diagnostic areas of CA are represented by irregular vascular channels, lined by atypical endothelium in a single row or several layers thick. Low-grade CA are well-differentiated lesions that retain some of the functional and morphologic features of normal vascular endothelium whereas poorly differentiated CA shows sheets of pleomorphic cells with distorted architecture, markedly pleomorphic nuclei, and brisk mitosis [9]. Immunohistochemically, various endothelial markers can be demonstrated depending on the degree of differentiation. Of these, CD31 is the most specific and sensitive marker of endothelial cell differentiation and is an important aid in diagnosis [9].

The rate of regional nodal involvement is said to be 20\%-30\%, which is higher than most other sarcomas [10]. Distant metastasis may occur in up to $50 \%$, mostly in the lung [11]. In this case diagnosed early, we did not detect lymph node involvement or metastasis to another organ. Delayed recurrence of CA at the distant sites has been reported, which makes regular, lifelong surveillance a must [6].

Total excision of the lesion with safety margins in healthy areas combined with radiation has been advocated as the treatment of choice. Larger lesions are often not amenable to surgery and are frequently treated with radiation alone. Adjuvant chemotherapy should be discussed on a case-by-case basis [12-14].

In summary, CA is an extremely rare tumor that is not often encountered by dermatologists, with a very high cutaneous invasive potential, worst prognosis and limited treatment options. Achieving local control and prevention of metastasis in CA is challenging. That's why this tumor should be considered in the differential diagnosis for any patient presenting with erythematous or bluise like lesion particulary on the face and scalp. Early diagnosis may lead to increased treatment options and a greater chance of survival.

\section{ACKNOWLEDGEMENTS}

The authors would like to acknowledge the patient. 


\section{Consent}

The examination of the patient was conducted according to the principles of the Declaration of Helsinki.

The authors certify that they have obtained all appropriate patient consent forms, in which the patients gave their consent for images and other clinical information to be included in the journal. The patients understand that their names and initials will not be published and due effort will be made to conceal their identity, but that anonymity cannot be guaranteed.

\section{REFERENCES}

1. Barnett CR, Bakr FS, Grossman ME. Cutaneous angiosarcoma with skin metasases and persistent bloody pleural effusions. Cutis. 2012;89:129-32.

2. Ito T, Uchi H, Nakahara T, Tsuji G, Oda Y, Hagihara A, Furue M. Cutaneous angiosarcoma of the head and face: a single-center analysis of treatment outcomes in 43 patients in Japan. J Cancer Res Clin Oncol. 2016;142:1387-94.

3. Deyrup AT, McKenney JK, Tighiouart M, Folpe AL, Weiss SW. Sporadic cutaneous angiosarcomas: a proposal for risk stratification based on 69 cases. Am J Surg Pathol. 2008;32:72-7.

4. Rao J, Dekoven JG, Beatty JD, Jones G. Cutaneous angiosarcoma as a delayed complication of radiation therapy for carcinoma of the breast. J Am Acad Dermatol. 2003;49:532-8.

5. Pawlik TM, Paulino AF, McGinn CJ, Baker LH, Cohen DS, Morris JS, et al. Cutaneous angiosarcoma of the scalp: A multidisciplinary approach. Cancer. 2003;98:1716-26.
6. Nishiwaki Y, Tada Y, Nakatani C, Yamashina Y, Shirai T, Miyagawa S. A case of angiosarcoma of the nose. J Dermatol. 2002;29:593-8.

7. Keizer RJ, Wolff-Rouendaal D, Nooy MA. Angiosarcoma of the eyelid and periorbital region. Experience in Leiden with iridium192 brachytherapy and low-dose doxorubicin chemotherapy. Orbit. 2008;27:5-12.

8. Cozzani E, Chinazzo C, Ghigliotti G, Pastorino C, Gasparini G, Parodi A. Cutaneous angiosarcoma: the role of dermoscopy to reduce the risk of a delayed diagnosis. Int. J. Dermatol. 2018;57:996-7.

9. Calonje E, Thomas B. Vascular tumors: Tumors and tumorlike conditions of blood vessels and lymphatics. Histopathol Skin. 2009;1007-56.

10. Bajaj S, Sharma PK, Sachdev IS, Bhardhwaj M. A Novel presentation of cutaneous angiosarcoma: a case report and review. Indian J Med Paediatr Oncol. 2017;38:363-6.

11. Gupta MD, Chakrabarti N, Agrawal P, Narurkar S. Angiosarcoma of the scalp. Indian J Plast Surg. 2009;42:118-21.

12. Young RJ, Brown NJ, Reed MW. Angiosarcoma. Lancet Oncol. 2010;11:983.

13. Gupta MD, Chakrabarti N, Agrawal P, Narurkar S. Angiosarcoma of the scalp. Indian J Plast Surg. 2009;42:118-21.

14. odor J, Orosz Z, Szabo E, Angiosarcoma after conservation treatment for breast carcinoma: our experience and a review of the literature. J Am Acad Dermatol. 2006;54:499.

Copyright by Faten Rabhi, et al. This is an open access article distributed under the terms of the Creative Commons Attribution License, which permits unrestricted use, distribution, and reproduction in any medium, provided the original author and source are credited.

Source of Support: Nil, Conflict of Interest: None declared. 